
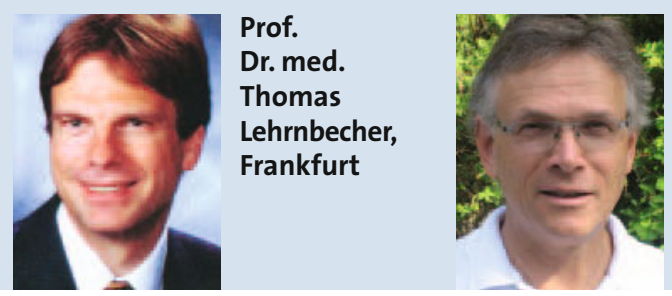

Dr. med.

Ulrich

Mutschler,

Hildesheim
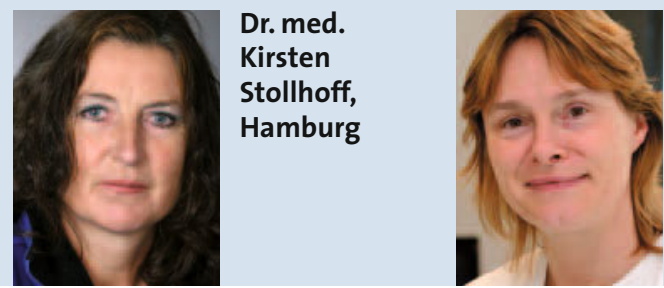

Hannelore

Willenborg,

Hannover

\section{Prophylaktisches Paracetamol schwächt Immunantwort}

Nicht selten wird zusammen mit der Impfung die vorbeugende Gabe von Paracetamol empfohlen. Wissenschaftler sind deshalb in einer in Lancet publicierten Studie der Frage nachgegangen, ob diese prophylaktische Gabe von Paracetamol einen Einfluss auf die Immunogenität der Impfungen hat.

$\mathrm{V}$ iele Kinderärzte verordnen bei Impfungen im ersten Lebensjahr Paracetamol. In der Regel wird die tatsächliche Anwendung dann auf eventuell auftretendes hohes Fieber und starke Unruhe beschränkt. Einige Pädiater jedoch empfehlen die Gabe von Paracetamol grundsätzlich, in der Hoffnung, dass die genannten Beschwerden gar nicht erst auftreten. Eine Arbeitsgruppe um Roman Prymula aus Prag untersuchte nun mögliche Auswirkungen dieser prophylaktischen Gabe.

Das gesamte Kollektiv der Untersuchung umfasste 459 gesunde Säuglinge. Nach Randomisierung erhielt etwa die Hälfte der Kinder prophylaktisch drei Gaben von Paracetamol als Zäpfchen (alle sechs bis acht Stunden in den ersten 24 Stunden nach der Impfung in einer Gesamtdosis zwischen 34 und $53 \mathrm{mg} / \mathrm{kg} / \mathrm{d}$ ). Die Impfung bestand aus der Sechsfachimpfung zusammen mit der zehnvalenten Pneumokokken-Vakzine sowie der Rotavirus-Schluckimpfung. Es handelte sich sowohl um Primärimpfungen als auch um Auffrischimpfungen.

Als Ergebnis wurde zunächst festgestellt, dass Temperaturen über $39,5^{\circ} \mathrm{C}$ in beiden Gruppen mit ca. $1 \%$ gleich häufig auftraten. Nur bei geringgradigem Fieber war die prophylaktisch mit Para- cetamol behandelte Gruppe im Vorteil: Fieber über $38{ }^{\circ} \mathrm{C}$ wurde hier bei $42 \%$ der Kindern nach einer Erstimpfung und bei $36 \%$ nach einer Auffrischimpfung beobachtet. Die entsprechenden Anteile in der nicht prophylaktisch mit Paracetamol behandelten Gruppe lagen bei 66\% bzw. 58\%.

Die Autoren untersuchten zusätzlich die Immunogenität der Impfstoffe durch Bestimmung der Antikörperkonzentrationen. Dabei stellte sich heraus, dass vorbeugend verabreichtes Paracetamol zu einer signifikanten Verminderung der Immunogenität der Impfung führte. Die Autoren raten daher von der prophylaktischen Gabe von Paracetamol bei zu impfenden Säuglingen ab.

Kommentar: Die prophylaktische Gabe von Paracetamol war besonders verbreitet als noch zellulärer Pertussisvakzinen verwendet wurden. Da bei den modernen Vakzinen hohes Fieber ohnehin kaum vorkommt und auch durch Paracetamol nicht seltener auftritt, darf man wohl auf die prophylaktische Gabe von Paracetamol bei Impfungen im Säuglingsalter endgültig verzichten, um die Immunogenität nicht unnötig abzuschwächen.

In derselben Ausgabe der Zeitschrift [Lancet 2009; 374:1305-6] bekräftigen

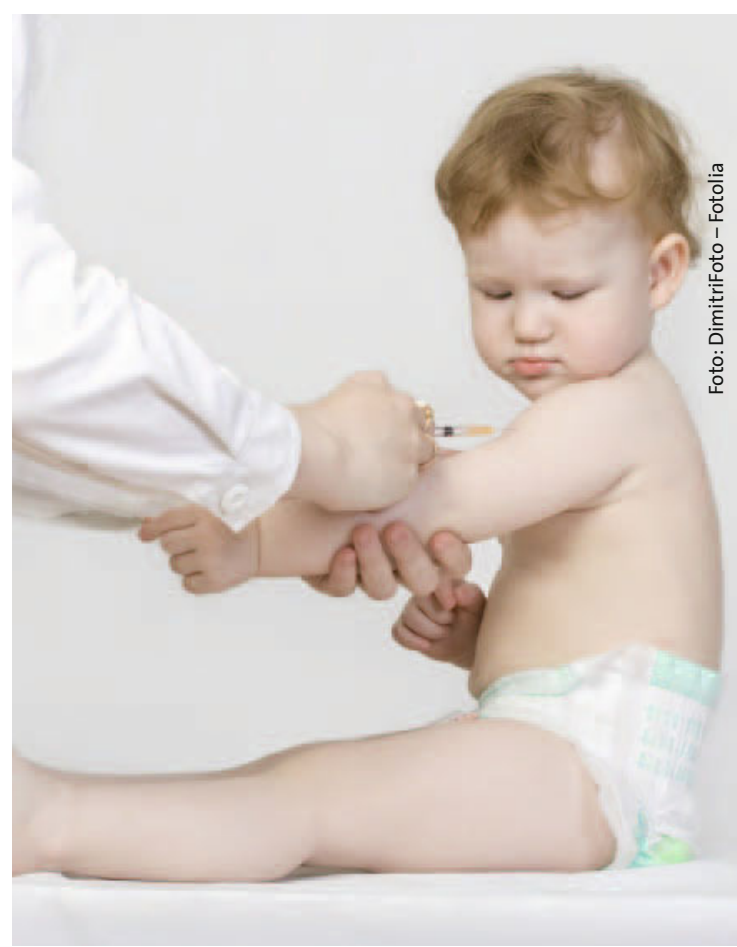

Paracetamol sollte hier nur nach Abwägung verordnet werden.

Chen et al. in einem Kommentar die Schlussfolgerungen der Autoren. Sie weisen darauf hin, dass unklar bleibt, ob andere Antipyretika denselben Effekt haben. An die Steigerung des Asthmarisikos durch reichliche Paracetamolgaben im ersten Lebensjahr sei ebenfalls erinnert.

Dr. Hartmut Koch

Prymula R et al. Effect of prophylactic paracetamol administration at time of vaccination on febrile reactions and antibody responses in children: two open-label, randomised controlled trials. Lancet 2009; 374: 1339-50 